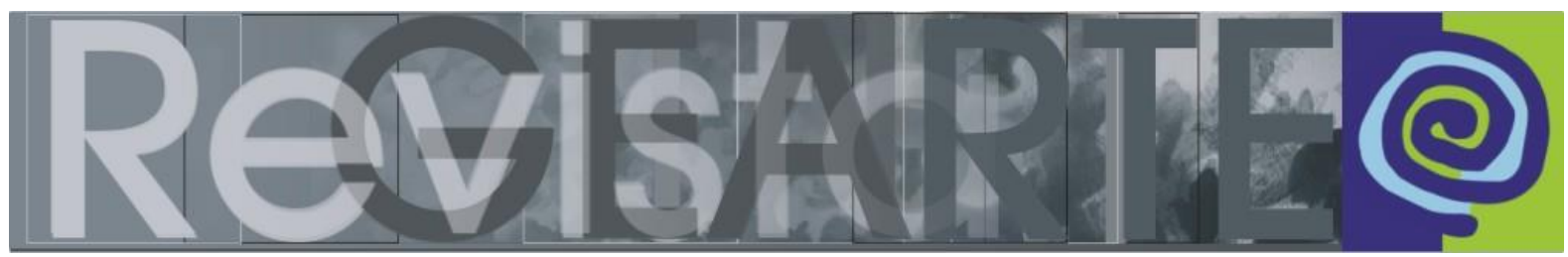

e-ISSN 2357-9854

\title{
Um estudo a partir da semiótica visual da pintura A Primeira Missa no Brasil, de Victor Meirelles ${ }^{1}$
}

\author{
Fabiane Villela Marroni (Universidade Católica \\ de Pelotas - UCPel, Pelotas/RS, Brasil)
}

\begin{abstract}
RESUMO - Um estudo a partir da semiótica visual da pintura A Primeira Missa no Brasil, de Victor Meirelles - A obra que nos propomos analisar neste artigo intitula-se A Primeira Missa no Brasil, de Victor Meirelles. Dada a sua expressiva dimensão, é considerada uma das telas de maiores proporções da arte brasileira produzida no século XIX. Como se sabe, a história do descobrimento do Brasil é repleta de contradições, dentre as quais se encontram questões sobre 0 acaso e a intenção dos portugueses que aportaram no Brasil em 1500. O quadro de Meirelles também se encontra envolto em divergências se levarmos em consideração a narrativa feita por Pero Vaz de Caminha, em sua carta ao rei de Portugal. A leitura dessa obra é trabalhada com o objetivo de apreender as categorias do plano da expressão homologáveis às categorias do conteúdo, com base nos pressupostos teóricometodológicos da semiótica discursiva de A. J. Greimas e seus colaboradores, mais especificamente à vertente da semiótica visual. Tais categorias da expressão foram relacionadas com oposições encontradas no plano do conteúdo, cujo resultado aproximou-se do que, em semiótica, são denominadas relações semissimbólicas. Como as análises propostas centraram-se apenas no textoquadro A Primeira Missa no Brasil, não houve a intenção de abordar o discurso ideológico desse quadro em oposição a outros discursos.
\end{abstract}

PALAVRAS-CHAVE

Semiótica Visual. A Primeira Missa no Brasil. Victor Meirelles.

ABSTRACT - A study based on visual semiotics of the painting A Primeira Missa no Brasil from Victor Meirelles - The work that we intend to analyze in this article is named A Primeira Missa no Brasil, from Victor Meirelles. Since its expressive dimension, it is considered one of the canvas of major proportion of Brazilian art produced in XIX century. As it is well-known, the history of the discovery of Brazil is full of contradictions, among them questions about the chance and the intention of the Portuguese that docked in Brazil in 1500. Meirelles'painting is also wrapped in divergences if we consider the narrative by Pero Vaz de Caminha in his letter to the king of Portugal. The reading of this art work is done with the objective of learning the categories of the expression plane homologable to the categories of content, based on the theoretical-methodological assumptions of the discursive semiotics of A. J. Greimas and his contributors, more specifically the visual semiotics perspective. Such categories of the expressions were related to oppositions found in the contents plane, whose results approximated to what, in semiotics, are called semisymbolic relations. As the analysis presented were focused on only on the text-painting A Primeira Missa no Brasil, there was no intention of approaching the ideological discourse of this painting in opposition to other discourses.

KEYWORDS

Visual Semiotics. A Primeira Missa no Brasil. Victor Meirelles.

1 Este artigo foi publicado, pela primeira vez, em 1999, no Caderno de Discussão do V Colóquio do Centro de Pesquisas Sociossemióticas (PUC-SP [PPGCOS] - USP [FFLCH] - CNRS). Aqui, é apresentado como uma segunda edição revisada e atualizada. 
Figura 1: A Primeira Missa no Brasil, Victor Meirelles, 1860. MNBA, RJ

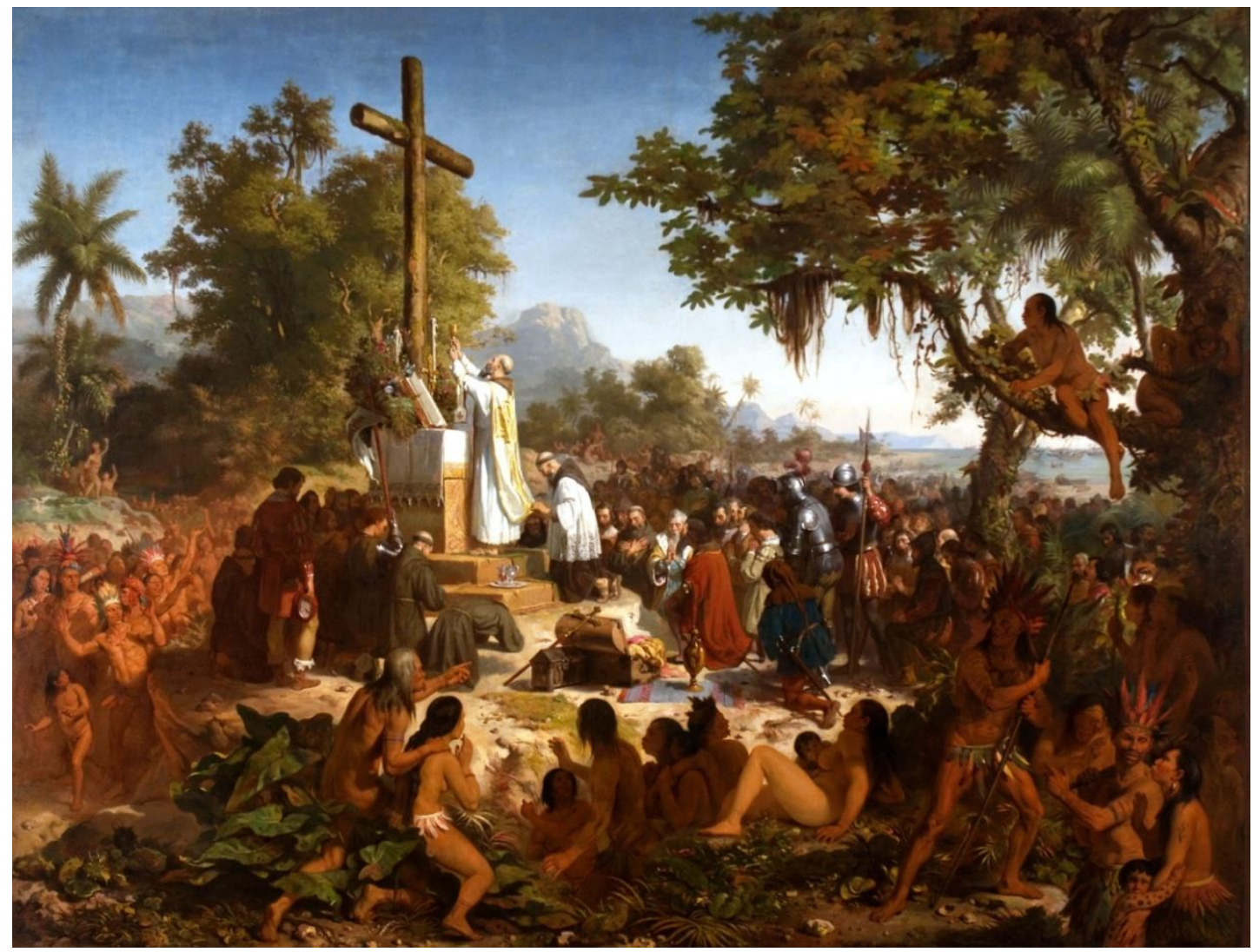

Fonte: http://www.museus.gov.br/wp-content/uploads/2012/06/PrimeiraMissaBR_VictorMeirelles.jpg

\section{Introdução}

Conta-nos a História que a esquadra de Cabral saiu de Portugal com destino à Índia. Lá, pretendiam os portugueses comprar especiarias e comercializar outros produtos. Além dessa incumbência comercial tinham, também, como propósito, implantar a religião cristã. Afastados da costa para evitar as calmarias, a esquadra de Cabral perdeu o rumo e, atravessando o oceano Atlântico, chegou ao litoral brasileiro, pensando seus tripulantes terem chegado à Índia. Por isso, ao avistarem os habitantes naturais da terra, os chamaram de "índios".

Ao desembarcar em terra firme, os soldados ostentavam uniformes coloridos e, muitos, carregavam suas armas. A tudo isso, os silvícolas assistiam ariscos e deslumbrados.

Logo, uma grande cruz foi erguida. Esta cruz foi feita pelos carpinteiros da esquadra, utilizando madeira da terra. Junto a ela foi colocado o escudo de Portugal e, em frente, armaram um altar coberto com toalha de renda portuguesa. Ali, em terra firme, seria rezada a primeira missa no Brasil e, para celebrá-la, foi designado o capelão da esquadra, Frei Henrique, da cidade de Coimbra.

Mansos e curiosos, os selvagens acorriam de todos os lados. Em torno, pela praia, por entre as moitas, sobre os galhos das árvores surgiam homens, mulheres e crianças. totalmente nus. Silenciosos, assistiam à cerimônia, tentando, alguns, imitar os gestos dos brancos,

Após a cerimônia litúrgica, o almirante Pedro Álvares Cabral declarou portuguesa e cristã a terra que descobrira. 
Este episódio religioso foi o batismo cristão da terra brasileira, que o grande pintor Victor Meirelles imortalizou no quadro "A Primeira Missa no Brasil”2.

A obra que analisamos intitula-se A Primeira Missa no Brasil, de Victor Meirelles. Dada a sua expressiva dimensão (2,68 m x 3,56 m), é considerada uma das telas de maiores proporções da arte brasileira produzida no século XIX.

Como se sabe, a história do descobrimento do Brasil é repleta de contradições, dentre as quais se encontram questões sobre o acaso e sobre a intenção dos portugueses que aportaram no Brasil em 1500. O quadro que aqui se propõe analisar também se encontra envolto em divergências, se levarmos em consideração a narrativa feita por Pero Vaz de Caminha em sua carta ao rei de Portugal, Dom Manuel. A primeira missa foi realizada em 26 de abril, domingo de Páscoa, no llhéu da Coroa Vermelha (Bahia) e, nela, a cruz ainda não havia sido "chantada". O célebre quadro de Victor Meirelles representaria, portanto, a segunda missa rezada em terra firme, a 1을 de maio, sexta-feira, o que contradiria o título.

\section{Estudo do significante da obra}

A organização do quadro A Primeira Missa no Brasil é realizada com base nas linhas estruturais que organizam o espaço da obra, produzindo, assim, um efeito de equilíbrio. Essa pintura encontra-se estruturada pela predominância de linhas horizontais, que reiteram a configuração retangular da obra. A primeira grande apreensão que se tem é feita por uma linha horizontal central, que a divide em duas grandes zonas.

Na primeira zona, tem-se uma linha contínua horizontal (horizontalidade) que, seguindo a mesma configuração da superfície do quadro, divide esta zona em outras duas subzonas paralelas (Fig.2).

$\mathrm{Na}$ primeira subzona (de baixo para cima), há uma predominância de triangulações (retilíneo) [Fig.3], a presença de linhas irregulares contínuas com contornos arredondados (curvilíneo) [Fig.4] e uma linha côncava (concavidade)

2 MORAIS, J. B. Leitura amena. In: GASTAL, Maria de Lourdes. Estudos Sociais e Naturais. 4.ed. Porto Alegre: Selbach, 1950. p.36-37. 
[Fig.5], que vai de uma lateral a outra do quadro. Na subzona superior, há uma reiteração das formas triangulares e rotundas, semelhantes às encontradas na subzona inferior, e uma linha convexa (convexidade) que, junto com a linha côncava da subzona inferior, estrutura a zona central da obra.

A segunda zona é constituída de uma linha contínua (horizontalidade), por linhas irregulares com contornos arredondados (curvilíneo); por uma linha contínua (verticalidade); perpendiculares horizontais e pelos vértices do conjunto de triangularizações (retilíneas).

Figura 2: Categoria eidética - linhas horizontais e verticais

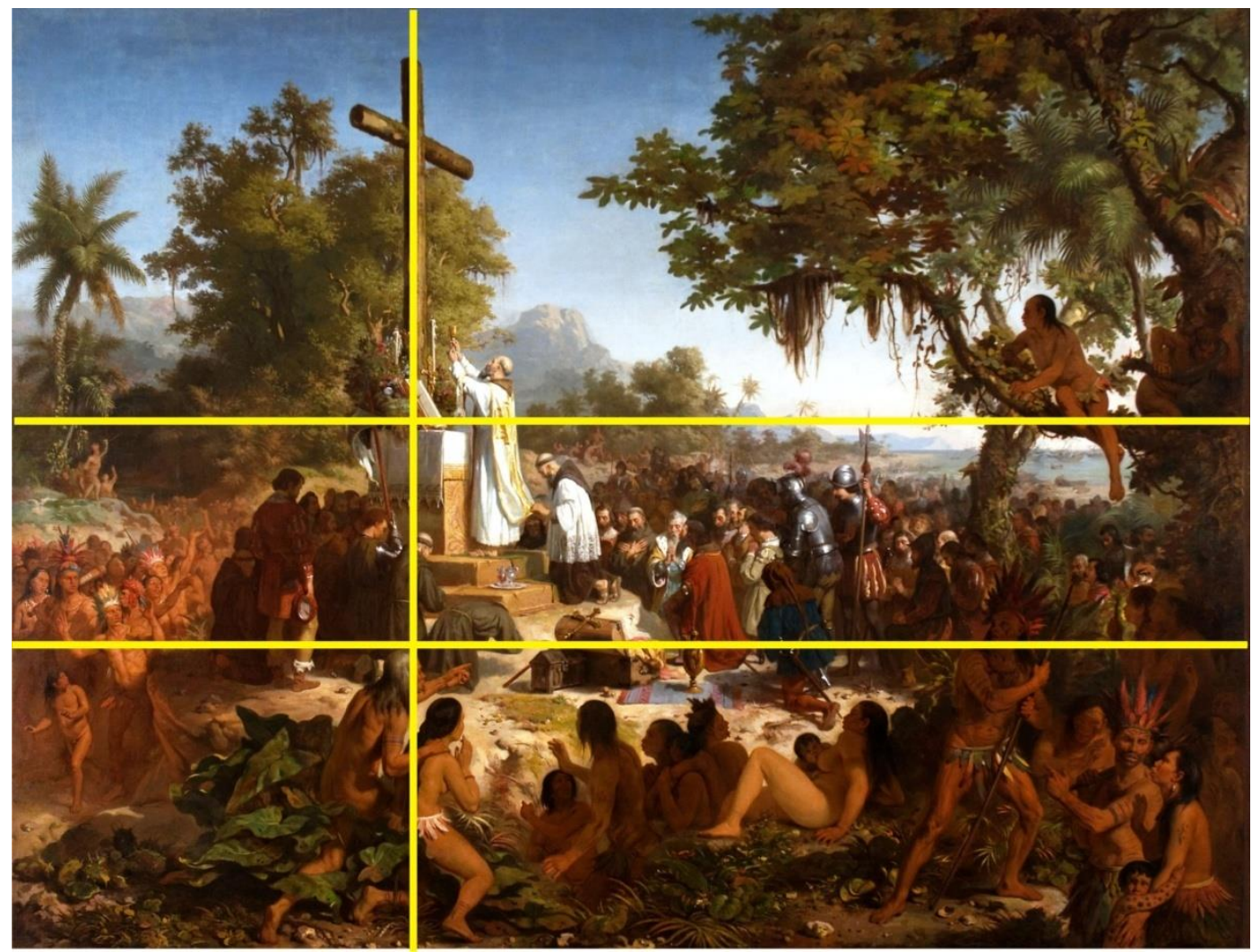

Fonte: Arquivo da autora. 
Figura 3: Categoria eidética - triangularizações

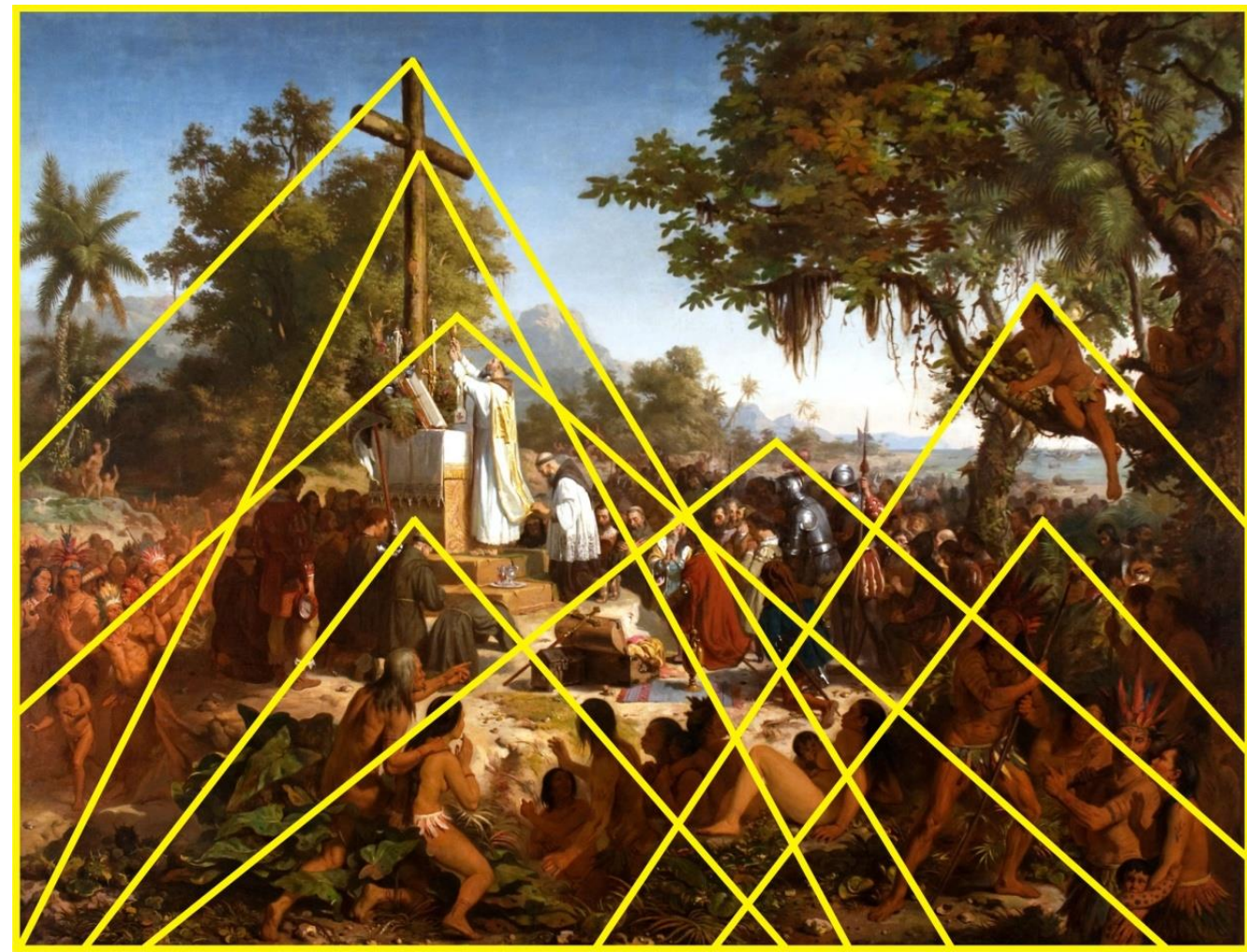

Fonte: Arquivo da autora.

Figura 4: Categoria eidética - contornos curvilíneos

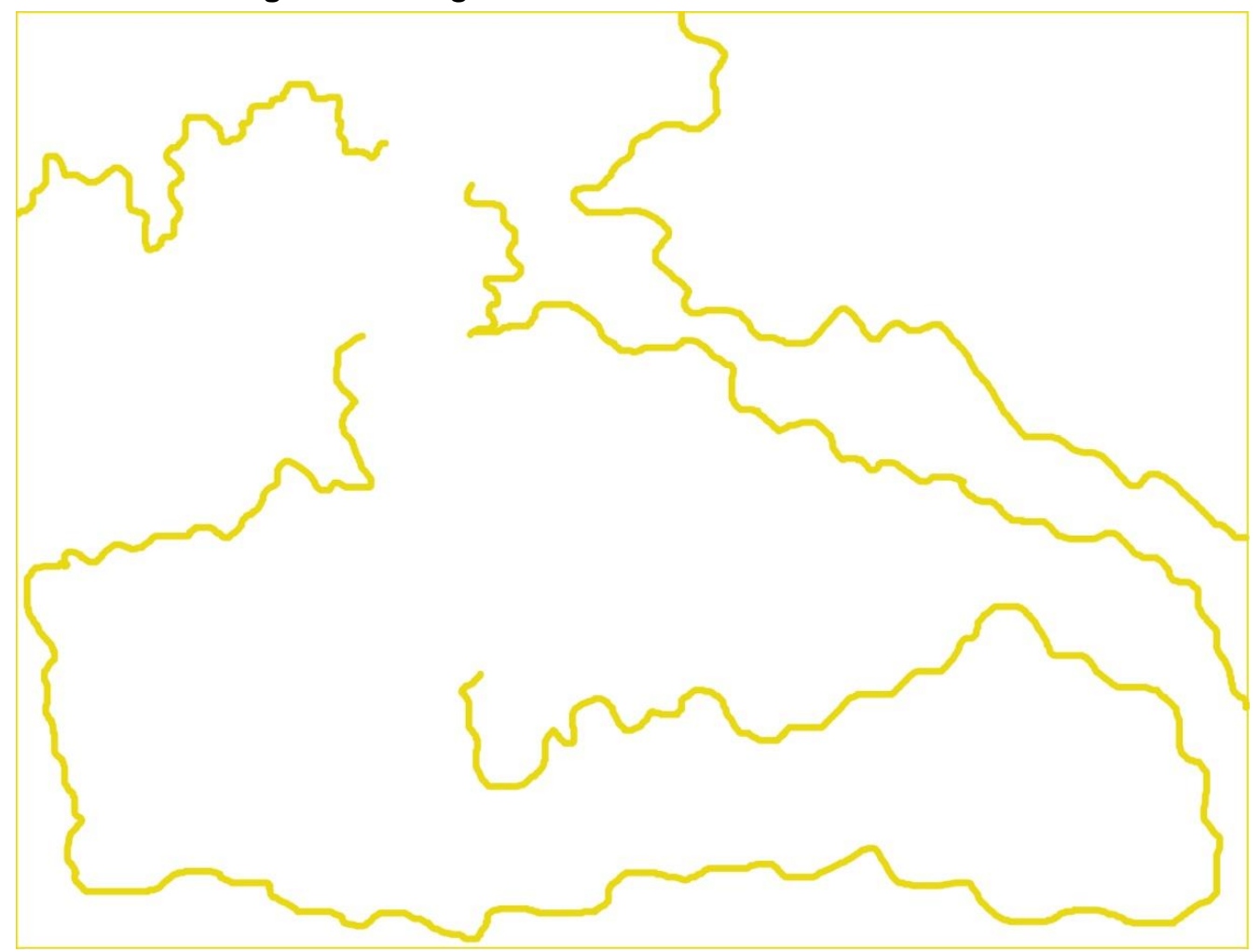

Fonte: Arquivo da autora. 
Figura 5: Categoria eidética - linhas côncava e convexa

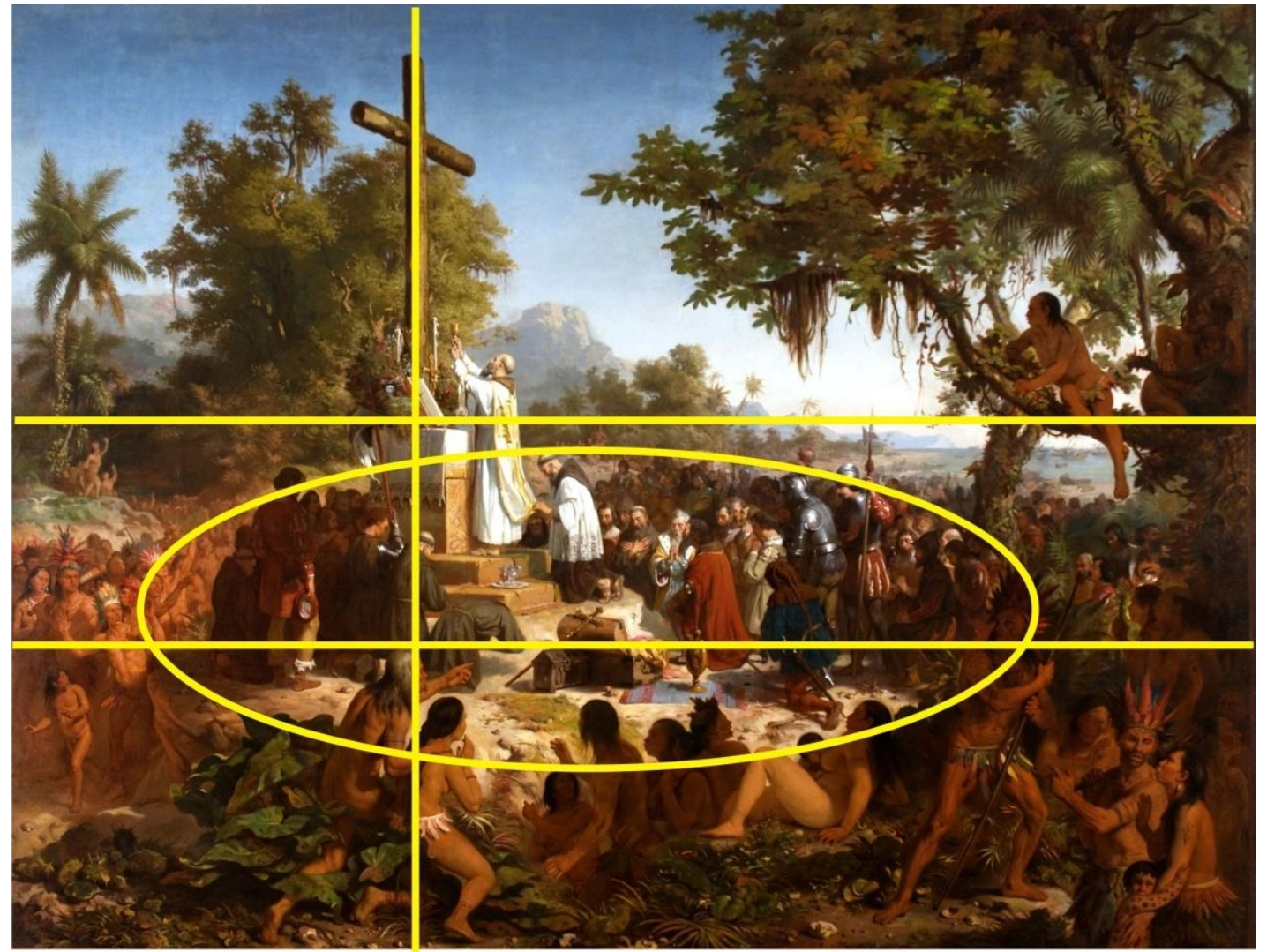

Fonte: Arquivo da autora.

É no jogo das cores, traduzidas em claros e escuros, que o espetáculo se revela no enunciado. O branco (claro) torna-se mais evidente pela presença das sombras constituídas na primeira zona.

Há um domínio de tons marrons sobrepostos aos tons verdes. O tom marrom dourado dá à pintura uma atmosfera sombria, reiterando esse conteúdo no aglomerado de índios, retratados, principalmente, à esquerda e à direita da tela (escuro). O vermelho, localizado na subzona superior deste mesmo plano, é usado em tom rebaixado pela velatura (mistura de verniz e pigmento) aplicada sobre a obra, dando-Ihe uma unidade cromática. O sentido dá-se, então, proporcionalmente, pelo tamanho das partes claras e escuras que compõem as unidades cromáticas, de acordo com o esquema apresentado abaixo: 


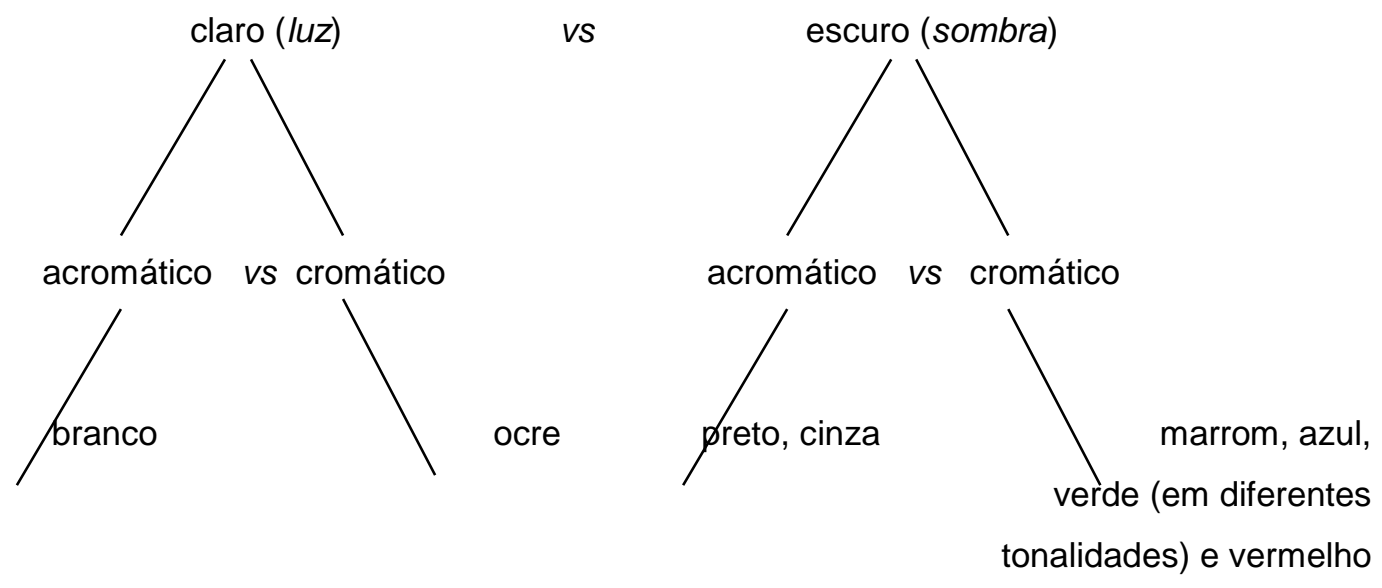

$\mathrm{Na}$ obra analisada, observa-se a presença de categorias eidéticas e cromáticas, organizadas na categoria topológica, relacionadas a seguir:

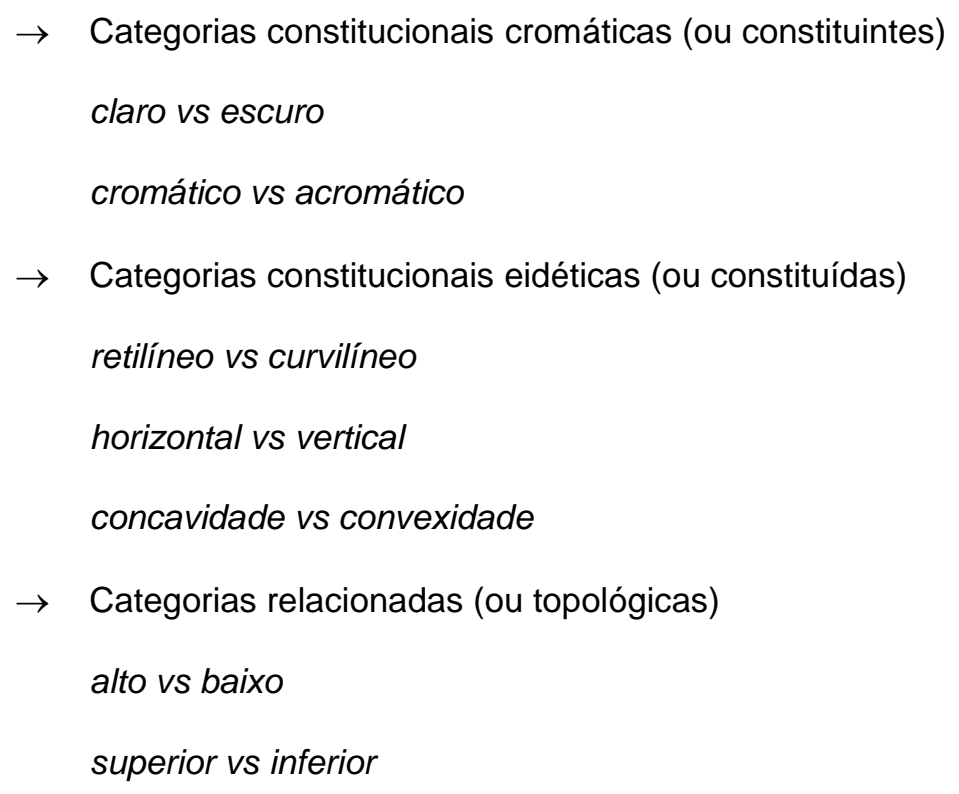

As grandes zonas horizontais da tela são cortadas pela vertical dominante da cruz, cujo efeito visual faz o contraponto à horizontalidade da obra. Por outro lado, a cena principal, a missa, encontra-se englobada na grande triangulação, forma que configura a composição central.

\section{Estudo do significado da obra}

A leitura dessa obra é trabalhada com o objetivo de apreender as categorias do plano da expressão, que são homologáveis às categorias do conteúdo. 
$\mathrm{Na}$ primeira zona, encontram-se várias figuras que parecem assistir, contemplativamente, à cena que se apresenta no centro da composição. No quadrante inferior, à direita, presenciam-se duas figuras, sendo que a localizada em posição mais baixa se volta à primeira e tem seu braço esquerdo apontando para o espaço central. A segunda figura, de perfil, parece escutar, pacientemente, o que a primeira figura estaria Ihe dizendo. A seguir, encontra-se uma figura de frente, em pé, cuja posição sugere certa instabilidade, pois tem o corpo apoiado em, apenas, uma das pernas e seu rosto levemente voltado para o lado. A disposição topológica dessa figura parece deslocar-se no espaço da tela, fazendo um contraponto à posição de repouso e estabilidade de uma figura feminina, que se apresenta a amamentar seu filho nesta mesma zona.

No segundo grupo de figuras, o tamanho é ligeiramente menor que o primeiro, o que produz um efeito de profundidade a essa cena, reiterado pela dimensão cromática. Esse grupo de figuras, que constitui a primeira zona da composição, tem a gestualidade como traço marcante.

Logo após a primeira zona, vê-se uma figura sentada no galho da árvore, que avança em direção à cruz, e cuja proxêmica parece indicar que ela (a figura do índio) se encontra em posição de assistente da cerimônia litúrgica.

No espaço central da obra, apresenta-se o altar, com a cruz toda em madeira, posicionada no foco de interesse.

Nos degraus do altar, encontram-se os celebrantes, cujas vestes refletem a luz que se contrapõem às sombras e penumbras que envolvem a cena central. Em seu entorno, dispõem-se os integrantes do reino português, cujos adereços parecem querer evidenciar a importância dessas figuras, enquanto os indígenas são apresentados no espaço periférico.

Em um tapete colocado sobre o chão de terra, no centro da composição, encontra-se, também, um baú que, aberto, deixa revelar as roupas desalinhadas que surgem do seu interior, enquanto sobre sua tampa, encontra-se uma espada, na qual é retomada a forma da cruz e, junto a essas figuras, vê-se um vasilhame de metal 
para guardar o vinho da celebração. A presença do tapete parece revelar a solenidade e o grau de respeito pelo ato religioso.

\section{O jogo do olhar}

A gestualidade das figuras é algo que desperta a atenção de todos aqueles que têm oportunidade de observar esta pintura. A direção do olhar que elas apresentam no espaço construído da tela constitui um poderoso artifício, que leva o observador ao centro da composição em que se encontra o altar da celebração.

Do mesmo modo que o olhar das figuras direciona o olhar do observador para o ponto central, ponto de interesse da cena, a gestualidade, traduzida pelos braços que apontam, também constitui um verdadeiro vetor que indica a direção para o centro da pintura.

Do lado direito do altar, encontra-se um grupo de figuras, cujo gesto reforça a solenidade do momento. Esse grupo exibe trajes, panos que denotam a importância dessas personagens, contrastando com a nudez dos corpos dos indígenas que assistem à cena. Essas mesmas figuras se encontram com as mãos cruzadas sobre o peito, em atitude de respeito e veneração, confirmada pelos olhos abaixados, reforçam a concentração durante o ato de fé. No lado contrário, encontra-se outro grupo de figuras que, de costas para o observador, volta-se para a celebração do ato.

A distribuição topológica dessas figuras sugere o ritmo desenvolvido na postura deles. O ritmo decrescente dessas figuras vai se fazendo por seu posicionamento, partindo do primeiro até culminar com o último, debruçado sobre o chão em atitude de verdadeira devoção e entrega. Vê-se, ainda, no nível topológico, o eixo de direções contrárias, traduzido pela figura do sacerdote que, ao levantar o cálice em direção à cruz, descreve um movimento contrário ao da outra personagem, encontrada ajoelhada no degrau do altar.

\section{O papel do enunciador e do enunciatário}

O fazer persuasivo utilizado pelo enunciador no ato de produção da manifestação textual, intitulada $A$ Primeira Missa no Brasil, conduz o enunciatário a 
um fazer interpretativo através da instalação de um dispositivo veridictório, isto é, de um fazer-crer ser verdadeiro, fazendo-o reconhecer as figuras do mundo.

É tamanha a força do simulacro construído, que leva o enunciatário a acreditar que as figuras apresentadas, "imitadas", no enunciado realmente representam uma "realidade".

Ao conceito de "imitação" que, na estrutura da comunicação se situa no âmbito do enunciador, corresponde o 'reconhecimento' que é próprio do enunciatário: "imitar", nas precárias condições que acabamos de assinalar, não tem sentido a não ser que as figuras visuais, assim traçadas, sejam oferecidas ao eventual espectador, para que as reconheça como configurações do mundo natural (GREIMAS, 1984, p. 23).

\section{Homologações de categorias}

A presença de categorias opositivas, encontradas através desta análise, levanos a elaborar várias considerações.

Em um primeiro momento, constata-se a cruz como um termo complexo. A madeira retirada da natureza e, posteriormente, trabalhada, levou-nos a encontrar a oposição natureza vs cultura. Tal oposição também é recuperada nas figuras descritas, representando, desta forma, "um modo de vida" dos sujeitos retratados: de um lado os índios, a natureza; de outro, os portugueses, a cultura.

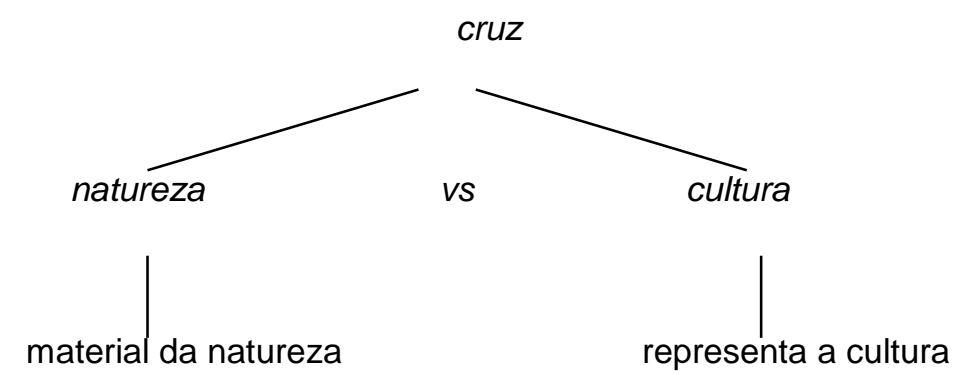

Verifica-se, também, que a divisão em duas zonas marcou, substancialmente, as categorias profano vs sagrado. Os índios, os portugueses, a presença de vegetação, os tons marrons e verdes evidenciaram a constatação da categoria terrestre. Já, na segunda zona, a presença dos tons azuis, em quase toda a sua extensão, e a cruz, que aparece por inteira no lado esquerdo da tela - como se 
estivesse servindo de elemento de ligação entre o céu e a terra - possibilitaram-nos caracterizá-la como sagrada.

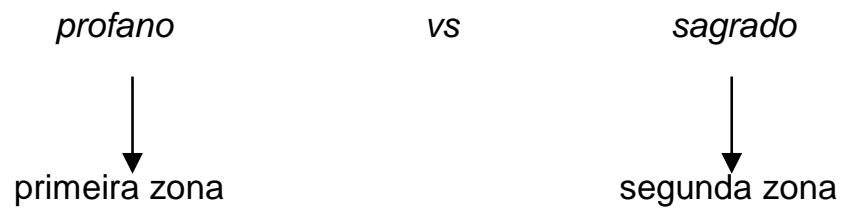

A divisão feita na primeira zona (respectivamente, primeira subzona e segunda subzona) e o jogo de linhas (convexidade vs concavidade) encontradas, fizeram-nos perceber um espaço central e um periférico (no espaço representado). O espaço central é dominado pelos portugueses. O celebrar da missa, a presença dos tripulantes e de objetos litúrgicos (culturalizado) são circundados por uma região periférica, tomada pelos índios em plena integração com a natureza (naturalizado).

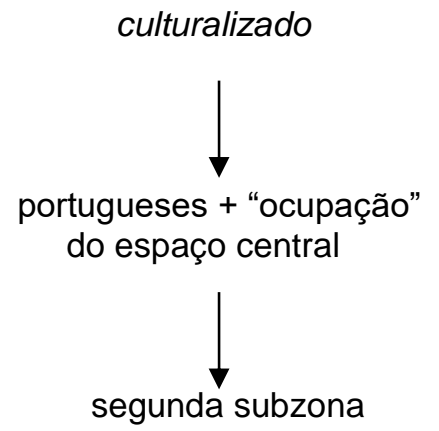

VS

naturalizado

O espaço central também é fortemente demarcado pela dimensão cromática. A grande luminosidade do centro, marcada pelos tons de ocre e branco, destaca o valor do acontecimento - a missa - em oposição ao espaço periférico, onde a penumbra, caracterizada pelo domínio dos tons terrosos, marca a presença do indígena.

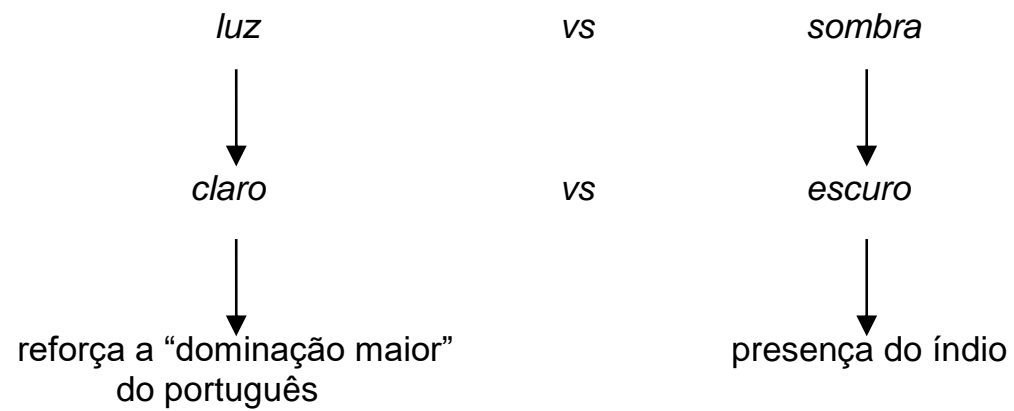




\section{Considerações finais}

A partir de textos que abordam a semiótica do visual, relacionados nas referências deste artigo, buscamos recuperar na pintura A Primeira Missa no Brasil as categorias que formam o plano da expressão e, desse modo, detectamos as seguintes: claro vs escuro/ cromático vs acromático/ horizontal vs vertical/ retilíneo vs curvilíneo/ concavidade vs convexidade/ alto vs baixo/superior vs inferior.

Em um segundo momento, verificamos a possibilidade de relacionar tais categorias da expressão com algumas oposições encontradas no plano do conteúdo (profano vs sagrado/ naturalizado vs culturalizado), cujo resultado aproximou do que, em semiótica, são denominadas relações semissimbólicas.

Como as análises propostas foram centradas apenas no texto-quadro $A$ Primeira Missa no Brasil, não houve a intenção de abordar o discurso ideológico desse quadro em oposição a outros discursos.

\section{Referências}

BARROS, Diana Luz Pessoa de. Problemas de expressão: figuras do conteúdo e figuras de expressão, Anais do 1 o colóquio Luso-Brasileiro de Semiótica, Universidade Federal Fluminense, Niterói, 1986.

BARROS, Diana Luz Pessoa de. Texto e Imagem, Linguagens, Porto Alegre, n.1, p.29-37, out. 1986. BARROS, Diana Luz Pessoa de. Teoria semiótica do texto. 5ed. São Paulo: Ática, 2011.

FIORIN, José Luiz. Elementos de análise do discurso. 13ed. São Paulo: Contexto, 2005.

$\mathrm{FLOCH}$, Jean Marie. Sémiotique plastique et language publicitaire, Documents, Paris, Groupe de Recherches Sémio-linguistiques, III, n.26, 1981.

GREIMAS, Algirdas Julien. Semiótica figurativa e semiótica plástica, Significação, São Paulo, n.4, p.1846, jul. 1984,

MARRONI, Fabiane Villela. Análise semiótica da pintura A Primeira Missa no Brasil, de Vitor Meireles de Lima. Caderno de Discussão do Centro de Pesquisas Sociossemióticas (Impresso), São Paulo, v. 1, n.1, p. 113-122, 1999.

OLIVEIRA, Ana Claudia de. Semioses pictóricas, FACE, São Paulo, v.4, n.2, p.104-145, jul./dez. 1995.

OLIVEIRA, Ana Claudia de. A dança das ordens sensoriais. In: LANDOWSKI, Eric.; DORRA Raul.; OLIVEIRA, Ana Claudia de. Semiótica, estesis, estética. São Paulo/Puebla: EDUC-UAP, 1999. 


\section{Fabiane Villela Marroni}

Possui graduação em Tecnologia em Processamento de Dados pela Universidade Católica de Pelotas (1995), aperfeiçoamento em Educação pela Universidade Federal de Pelotas (1997), mestrado em Comunicação e Semiótica pela Pontifícia Universidade Católica de São Paulo (2001) e doutorado em Comunicação e Semiótica pela mesma Instituição (2008). Professora adjunta da Universidade Católica de Pelotas. Atua com temas relacionados à Semiótica Discursiva (Semiótica Visual e Semiótica Sincrética), Tecnologias Digitais de Informação e Comunicação. Leciona no Programa de PósGraduação em Letras da UCPel, atuando nas áreas de Semiótica Discursiva, principalmente vertentes relacionadas ao sincretismo de linguagens, e Tecnologia Digitais de Informação e Comunicação. É pesquisadora do Centro de Pesquisas Sociossemóticas da PUC-SP, desde 1998, e líder do Grupo de Pesquisa em Acervo Digital (GrAD), vinculado ao CNPq.

E-mail: fvmar@terra.com.br

Currículo: http://lattes.cnpq.br/0405454451123282 